\title{
Contribuição à Inclusão Escolar de Pessoas com Necessidades Especiais
}

\author{
Rodrigo Barroca
}

\section{Resumo:}

Baseado no conceito de Educação como responsabilidade de todos, pautamo-nos em rever nosso trabalho cotidiano dentro de uma Unidade Básica de Saúde com o fim de verificar em que medida ele desenvolve suas potencialidades a favor da inclusão escolar de pessoas com necessidades educacionais especiais. $\mathrm{O}$ trabalho se propõe a superar os obstáculos que surgem no âmbito da competência dos trabalhadores da Unidade Básica de Saúde. Internamente, foram revistos os casos de pacientes considerados como portadores de deficiência, visando sua classificação diagnóstica através do GID IO para a geração de mais pormenorizada demanda educacional, o que é necessário para orientar as políticas de atendimento à essa parcela da população que todos sabemos ser expressiva no Brasil. Foram bem sucedidos os encontros entre profissionais da educação e da saúde visando trocas de experiências e vivências. Casos específicos de indivíduos que eram atendidos pela Escola e pela Unidade Básica de Saúde foram discutidos e algumas estratégias de atendimento foram planejadas. Daí, a confiança de que oportunizar este tipo de encontro de trocas de experiências profissionais podem contribuir para a aceleração do aprimoramento do atendimento escolar e de saúde, fundamentais ao ser humano, razão pala qual as humanidades ora se põem em diálogo.

Palavras - Chave: Saúde, educação, intersetorialidade, inclusão escolar, especial. 


\section{Introdução}

A legislação atual brasileira, mais especificamente o artigo 205 da Constituição Federal de 1988, estabelece que "a educação, direito de todos e dever do Estado e da Família, será promovida e incentivada com a colaboração da sociedade, visando ao pleno desenvolvimento da pessoa, seu preparo para o exercício da cidadania e sua qualificação para o trabalho." Segundo Souza e Prieto (2007), a questão central seria a conquista de uma educação escolar de qualidade para todas as crianças e jovens, capaz de garantir sua permanência na escola e apropriação/produção de conhecimento, tendo como alvo possibilitarlhes participação na sociedade.

Entretanto, embora esta legislação já devesse contemplar todos os cidadãos, observa-se que, historicamente, esse direito não vem sendo garantido a todos. Daí a necessidade de se ter, na legislação, dispositivos que buscam regulamentar as condições necessárias para que seja minimizada ou até superada a exclusão social e educacional a que são submetidas certas parcelas da população. Com este fim, tem-se previsto o "especial" na educação referindo-se a "condições que possam ser necessárias a alguns alunos para que se viabilize o direito de todos a educação."(SOUZA; PRIETO, 2007, p. I23)

O documento Diretrizes Nacionais para a Educação Especial na Educação Básica, aprovado em II de setembro de 200I pela Câmara de Educação Básica do Conselho Nacional de Educação (CEB/GNE), ao se referir aos alunos que, em tese, demandariam atendimento educacional em recursos especiais, define "educandos com necessidades especiais os que, durante o processo educacional, apresentarem: dificuldades acentuadas de aprendizagem ou limitações no processo de desenvolvimento que dificultem o acompanhamento das atividades curriculares, vinculadas ou não a uma causa orgânica específica; dificuldades de comunicação e sinalização diferenciadas dos demais alunos, demandando a utilização de linguagens e códigos aplicáveis; altas habilidades/superdotação, grande facilidade de aprendizado que os leve a dominar rapidamente conceitos, procedimentos e atitudes". (BRASIL, 200Ia apud SOUSA; PRIETO, 2007, p. I25)

No entanto, mesmo se pusermos de lado os debates conceituais a respeito do que afinal seria o "especial" na educação, vemos na prática que muito se tem a caminhar no sentido de garantir uma educação de qualidade para todos. Segundo Silva (2003), no que diz respeito à educação especial, essa dificuldade se traduziria em baixíssimo atendimento de grandes parcelas de sua clientela, entre elas: a de zero a três anos, a de pessoas com quadros de multideficiências ou com quadros associados; e a de adultos, sem nenhum tipo de atendimento. Somar- 
se-iam a isso a falta de profissionais com um mínimo de formação qualificada; a discrepância dos tipos de atendimento ofertados nas diversas regiões do país; a confusão conceitual- em que não se sabe de fato o que se tenta explicar; e a total e completa desarticulação entre o núcleo da educação especial e o corpo da Educação. Além disso, o desenvolvimento de uma proposta menos assistencialista e mais voltada de fato para o processo educacional estaria ainda longe de ser alcançado.

\section{Justificativa}

Este trabalho, idealizado como um trabalho de campo da disciplina de "Política e o Organização da Educação Básica no Brasil" (EDA 463) é realizado por licenciando em filosofia que trabalha como médico, especializado em medicina de família e comunidade, do programa de saúde da família, vinculado à Casa de Saúde Santa Marcelina.

Embora muitas outras propostas fossem possíveis, esta idéia surgiu como uma maneira de conciliar a obrigatoriedade deste trabalho para a licenciatura à possibilidade de, ao realizar o estágio, poder, além disso, utilizar-se dele como um incentivo, um exemplo, uma motivação adicional para oferecer algum avanço concreto ao atendimento educacional de alguns indivíduos "com necessidades especiais" residentes na área geográfica de responsabilidade profissional da equipe de saúde da família em que já trabalha o licenciando.

As políticas educacionais envolvidas nesse assunto poderiam ser melhor e mais motivadoramente compreendidas dentro deste contexto prático e interdisciplinar. Reflexamente, o resultado efetivo deste esforço de propiciar esse melhor atendimento educacional a um determinado grupo de indivíduos "concretos" já conhecidos desta determinada equipe de saúde, mostrar-se-ia estar de fato intrinsecamente dependente da soma coordenada das atuações de múltiplos profissionais de diversas áreas da saúde, educação e assistência social, para citar apenas as mais diretamente envolvidas, além de seus diversos e respectivos gestores. Inclusive, como debateremos adiante, coordenar estas plurais atuações constitui desafio no qual deságuam grande parte dos esforços nesta área, razão por que julgamos pertinente citar essa dificuldade já nas justificativas deste trabalho.

Pautados pela idéia de que a educação seja mesmo responsabilidade de todos, dispusemo-nos a rever nossas atuações individuais, não só como futuros educadores, mas também como profissionais e, ainda mais fundamentalmente, como seres humanos do presente, que nem só vivem, nem só trabalham, nem só estudam, e nem só compõem suas famílias, e, por isso, não podem, não querem se esquivar de sua parcela de responsabilidade perante estes indivíduos específicos 
que, assim como nós e todos os demais, são os frutos e as sementes de toda a sociedade.

Por estas razões, e como não poderia aqui deixar de explicitar e de agradecer, a concretização deste trabalho envolveu diversos profissionais: enfermeiros, médicos especialistas, auxiliares de enfermagem, agentes comunitários de saúde, fisioterapeutas, psicólogos e fonoaudiólogos, além de gerentes de unidade, coordenadores e idealizadores do programa de atenção primária à saúde da Casa de Saúde Santa Marcelina. Ainda além destes, contamos com o apoio de profissionais da área da educação da Prefeitura do Município de São Paulo e do Estado de São Paulo, que colaboraram desde a idealização do trabalho até a execução das visitas de campo que constituíram o estágio, mais propriamente dito, sem o que este estudo de "Política e Organização da Educação Básica no Brasil" fatalmente se descaracterizaria. A todas estas pessoas, ao professor Juca Gil, desta disciplina (EDA 463), que mais diretamente vem nos orientando, e, principalmente, aos munícipes, a quem se destina este esforço, gostaríamos de declarar nossa sincera gratidão e expectativa de que, a partir de gestos como estes, consigamos na realidade, e não apenas em leis ou em ideais, um mundo melhor e mais digno para todos.

\section{Objeto da investigação}

São objeto desta investigação as políticas educacionais voltadas ao atendimento escolar de pessoas com necessidades especiais. Mais particularmente, são objeto deste estudo os habitantes com necessidades educacionais especiais da área geográfica número 6, da UBSF Jd. Soares (atendida por uma equipe multidisciplinar regular do programa de saúde da família), e o atual quadro individual de inserção escolar destes indivíduos, enfocando tanto as responsabilidades governamentais como as familiares para o alcance desta meta.

\section{Objetivo geral}

Elaborar, para cada caso individual apontado pela referida equipe de saúde, e em comunhão com as diretrizes governamentais para a educação, uma proposta particularizada de intervenção, que possa ser efetivada em curto prazo, com o objetivo de otimizar as possibilidades de efetiva inserção escolar ou ocupacional destes indivíduos.

Estudar, ao longo deste esforço prático, as políticas educacionais e os aspectos organizacionais relacionados ao atendimento de alunos com necessidades educacionais especiais em nosso país. 


\section{Procedimento de coleta de dados}

A pesquisa foi realizada a partir da chamada área 6 da Unidade Básica de Saúde da Família Jardim Soares, Guaianases, São Paulo-SP, vinculada à Casa de Saúde Santa Marcelina. Através do auxílio da equipe de saúde, e, em especial, dos Agentes Comunitários de Saúde, foram inicialmente identificados e arrolados os indivíduos que fossem "portadores" de algum tipo de deficiência física ou mental.

Sabíamos, contudo, o quanto essa classificação seria difícil do ponto de vista conceitual e filosófico. Do ponto de vista educacional então, nem teríamos, sozinhos, como estabelecer. Porém, pensamos em estudar os indivíduos que aparecessem elencados pela equipe, e, individualmente, o que poderíamos melhorar ao seu atendimento em saúde e educação, sem nos deter em pormenorizações teóricas que, se por um lado belas e importantes, por outro, no mais das vezes, pouco contribuem para melhorar de fato a vida de quem é por elas conceituado.

Após elaboração desta lista por parte de cada um dos seis agentes comunitários de saúde, responsáveis por cada uma das seis micro-áreas geográficas que compõem a área de responsabilidade de uma equipe de saúde da família, iniciamos o trabalho médico de análise clínica de cada um desses casos para permitir a classificação dos casos dentro do que é conhecido como CIDıo (World Health Organization, 2006), a décima versão da classificação internacional de doenças. Esta classificação é necessária à emissão de laudos médicos tanto para a obtenção de transporte especializado, como para a obtenção de benefícios previdenciários. É útil para referenciar o caso entre especialistas da área da saúde e, entre outras coisas, é exigida nos laudos usados para ingressar e manter as crianças nas chamadas classes especiais. Outras classificações, incluindo a GIF, poderiam ser utilizadas, contudo a CID é a que, no momento possui maior aplicabilidade dentro do contexto das Unidades Básicas de Saúde e, além disso, se bem aplicada, fornece já informação bastante específica sobre a condição do aluno, cujas particularidades podem ser posteriormente melhor avaliadas.

Algumas destas consultas foram realizadas em consultório, outras no domicílio, principalmente devido a dificuldades de transporte e acomodação de alguns indivíduos. Para outras, já consultadas previamente, bastou a observação das anotações contidas nos prontuários.

Dentre os indivíduos descartados nesta etapa destacamos um grande número de pacientes adultos, já fora da chamada idade escolar, para os quais ficamos de formular algum trabalho futuro de inserção social. Neste grupo, é digno de nota o grande número de pacientes que foram classificados como deficientes por sequelas motoras de acidentes vasculares encefálicos, mazela que pode ser, no mais das vezes, prevenida com controle da pressão arterial e cessação do tabagismo. 
Ao final desta "triagem", com o perdão a alguma possível imperfeição de informação, que é justamente o que pretendemos aprimorar, chegamos a uma lista de apenas cinco indivíduos, cujas identidades permanecerão em sigilo, para os fins deste relatório, embora sejam descritas, em conformidade com os objetivos e com a justificativa do mesmo, as particularidades técnicas de cada um:

A primeira, que optaremos aqui por não identificar, II anos, é portadora de paralisia cerebral, CID IO: G80, tem dificuldades motoras, para transporte e acomodação, contudo, sua capacidade para desenho, escrita, e cognitiva parecem normais. Programamos a elaboração de laudo para obtenção de transporte especial (ATENDE) e abordamos a família com uma visita multidisciplinar, de troca de experiências entre profissionais e familiares, exaltando, dentro de uma perspectiva de realidade e de otimismo conscientes, as potencialidades da criança e as responsabilidades da família em seu processo educacional, de modo a incentivá-los a não desistir da escola, pois já haviam conseguido matrícula na escola regular.

A segunda, 9 anos, tem uma hemoglobinopatia e um déficit cognitivo moderado. Do ponto de vista que tange a escolarização, fizemos seu laudo com o CID IO: F79 (retardo mental não especificado). Já havia conseguido matrícula na escola regular, mas, de fato, concordamos com a família, a excessiva agitação psicomotora demonstrada pela menina deve dificultar muito sua adaptabilidade à turma. Encaminhamos à atendimento psicológico e ficamos de procurar, para ela, adaptação em turma "especial" cuja referência local nos comprometemos a obter.

O terceiro, 3 anos, também portador de paralisia cerebral (G80), tem severo comprometimento motor: não anda, não fala, firma o corpo apenas parcialmente e com dificuldade, pois seus movimentos tendem a espasticidade, o que torna, inclusive, mais difícil a avaliação de sua capacidade cognitiva. Após a inspeção destas informações contidas em prontuário médico, planejamos fazer novo contato com esta família, para, após reexaminarmos a criança, agora com o enfoque em suas possibilidades educacionais, encaminharmos para a C.E.I. com parecer médico e de fisioterapia, nos disponibilizando para qualquer contato futuro complementar. Porem, até o momento da elaboração deste relatório não conseguimos ainda efetivar o retorno desta família, que tem pouca disponibilidade de horário devido ao trabalho da mãe e, segundo informação do Agente Comunitário de Saúde, parece estar recebendo atendimento em uma entidade filantrópica especializada.

A quarta e a quinta, irmãos de IO e I5 anos, ambos com deficiência auditiva (H9o), são matriculados e frequentam turma "especial" na região. Para eles 
também foi feito o laudo para a solicitação de isenção tarifaria, ao qual têm direito em virtude dessa deficiência específica. Eles já se aproximam de ou já ultrapassam em muito a idade de conclusão do ensino fundamental I e necessitam de outra unidade educacional que lhes permita dar seguimentos a seus estudos. Seguindo indicação da família, no intuito de cumprir nossos objetivos, tanto da pesquisa de campo, como para a melhoria do atendimento a essas pessoas específicas, fomos visitar a E. E. Humberto Dantas, em Guaianases, São Paulo.

Segundo informação obtida no local, esta unidade educacional tem em média 600 alunos, divididos em, no momento, 22 turmas, com até 32 alunos por classe. Cada turma perfaz o período de 4 hs de estudo. Possuem duas turmas das chamadas classes "especiais": uma para déficits cognitivos em geral, ou "DM" no jargão corrente, e uma para "DA", crianças com déficits auditivos, cada uma com idealmente até dez alunos em cada. Os materiais diferenciados necessários são enviados pela secretaria da educação. A formação dos professores tem a participação das professoras coordenadoras de oficinas pedagógicas especiais. Recentemente, a secretaria estadual teria criado o "CAPE", Gentro de Apoio Pedagógico Especializado. Esta secretaria tem já também um projeto, com algumas experiências, de atendimento pedagógico residencial aos portadores de necessidades especiais para os quais é mais difícil a locomoção.

Uma das queixas mais frequentes das professoras de salas especiais que foram entrevistadas é com relação a habilidade necessária para lidar com a agressividade e com o comportamento libidinoso de alguns alunos. Este problema, segundo as professoras, se torna particularmente mais flagrante com o aumento da média de idade dos mesmos, consequente talvez à escassez e à dificuldade de manter equipamentos educacionais habilitados a dar sequência ao trabalho desenvolvido naquele local.

\section{Discussão}

É verdadeiro que, realmente, se lidar com a própria sexualidade e agressividade já não fossem desafios suficientes, quem dirá ter que refletir do ponto de vista educacional sobre a sexualidade de educandos com necessidades especiais. E, afinal, como impor os limites necessários à agressividade que, recentemente, vêm sendo estudada sob a denominação de desorganização do comportamento motor ou de desorganização do comportamento verbal, quando é somente este o modo pelo qual o educando ofende os que interagem socialmente com ele?

São verdadeiramente questões difíceis de serem abordadas tanto do ponto de vista prático como do conceitual. Para o médico também poderia ser muito difícil, e de pouco benefício, ter que classificar como "normais" ou "patológicas" 
tais comportamentos individuais, que, na imensa maioria das vezes, não podem, nem do ponto de vista da técnica, e nem no da ética à qual deve estar conciliada, ser simplesmente eliminados com o uso de uma ou outra medicação. Entretanto, este comentário geral não exclui que medicações, corretamente orientadas, possam ser benéficas em alguns casos particulares.

Assim, em consonância com os profissionais da educação com quem tivemos oportunidade de dialogar, e com quem muito aprendemos, acreditamos que tanto do ponto de vista médico, como do educacional, estas reflexões sobre a agressividade, sobre o comportamento sexual, e sobre o papel dos diversos educadores em cada contexto individual são, sem dúvida, questões de grande pertinência, dentre várias outras que poderiam também ter sido discutidas durante a realização deste estágio.

Uma elaboração eficaz com a família e com o ambiente que rodeia o indivíduo em questão já há muito tempo foram considerados indícios da qualidade do ensino de alunos com necessidades educacionais especiais (SKRTIG et al., I996 apud SAINT-LAURENT, I997). Contudo, para Saint-Laurent (I997), seria de responsabilidade dos agentes escolares dividir com os parentes um vocabulário e uma compreensão das tarefas de aprendizagem envolvidos no apoio ao aluno. Também Mazzotta (2008), ressalta, neste seu artigo, quando resume suas recomendações para uma operacionalização, a importância de se procurar uma uniformização terminológica e de condutas para os diversos setores envolvidos nas políticas públicas para a educação de pessoas com deficiências ou com altas habilidades/superdotação. Sem dúvidas, pelo que pudemos abstrair de nossas visitas a instituições educacionais, este é um ponto crucial ao objetivo de educar alunos com necessidades especiais, e, à falta de comunicação, e mesmo à discórdia, não vemos existir saída outra que não a do diálogo e do entendimento entre os múltiplos profissionais e às famílias envolvidas em cada contexto.

Além deste desafio coletivo, gostaríamos de comentar alguns aspectos motivacionais que, se bem valorizados, podem certamente fazer a diferença para cada um dos indivíduos envolvidos neste processo. Segundo Jannuzzi (2008), os funcionários da instituição escolar deveriam lutar contra a banalização de alguns valores apregoados pelos meios de comunicação de massa, deveriam resistir à desesperança de um mundo cada vez mais povoado, no qual parece haver lugar para a subsistência apenas de poucos, e socializar as descobertas, ato que a cultura universal vislumbrou e que continua sendo fundamental ao desenvolvimento das capacidades humanas.

Também Cauz (s/d) salienta que muitas das críticas à inclusão situamse nas relações entre a condição social das pessoas que apresentem necessidades 
especiais e o processo atual de globalização caracterizada pelo incremento da competitividade. Essa competitividade atualmente valoriza êxito acadêmico, o rendimento e a capacidade de competir e parece realmente impossível defender, nessa sociedade capitalista, a inclusão, meta que só pode ser viabilizada se baseada em valores tais como a cooperação, a solidariedade e o respeito.

\section{Considerações finais}

Entretanto, apesar desta e de outras dificuldades que poderiam ter sido recordadas durante a execução deste trabalho, julgamos conjuntamente que, a partir de encontros como estes, podemos sim contribuir para criar caminhos verdadeiros para a melhoria do atendimento global a estes e a outros indivíduos, além de tornar melhores, mais dignos e mais gratificantes também nossos trabalhos e, consequentemente, nossas vidas, partes que são de um todo interdependente e indissociável que compomos, ao qual somos muito gratos e perante o que pretendemos honrar a parcela de responsabilidade que nos tem sido quotidianamente investida. Isso pode perfeitamente acontecer sempre que profissionais das diferentes esferas e áreas de trabalho, e principalmente os que compartilham uma mesma área ou esfera de atuação, possam compartilhar não só informações, mas, acima de tudo, seus propósitos e suas disponibilidades para mudança.

\section{Referências Bibliográficas}

CAUZ, K.. P. L.; IACONO, J. P. A Inclusão Escolar de Crianças com Necessidades Educacionais Especiais no Município de Cascavel - Pr. Disponível em: <http://www.pr.senai.br/portaleducacional/uploadAddress/A_ inclus\% $\mathrm{C}_{3} \% \mathrm{~A}_{3}$ o_escolar_de_crian\%C3\%A7as\%5B23426\%5D.pdf $>$ Acesso em: I9 set.. 2008.

JANNUZZI, G.M. Políticas públicas de inclusão escolar de pessoas portadoras de necessidades especiais: reflexões. Revista GIS, Rio de Janeiro, out. 2004. Disponível em: 〈http://www.ltds.ufrj.br/gis/januzzi/januzzi2.htm〉. Acesso em: I9 set.. 2008. 
MAZZOTTA, M.J.S. Identidade dos Alunos com Necessidades Educacionais Especiais no Contexto da Política Educacional Brasileira, Revista de Educação da Universidade Federal Fluminense. Educação Especial e Inclusiva. Rio de Janeiro, n. 7, p.II- I8, maio/2003. Disponível em: <http://intervox.nce. ufrj.br/ elizabet/identidade.htm> Acesso em: I9 set. 2008.

SAINT-LAURENT, L. A Educação de Alunos com Necessidades Especiais. In: MANTOAN, M. T. E. e cols. A Integração de pessoas com Deficiência: Contribuições para uma reflexão sobre o tema, Ed. São Paulo: Memnon, I997, p. $67-76$.

SILVA, S. Educação Especial - Entre a Técnica Pedagógica e a Política Educacional. In: SILVA, S.; VIZIM, M. Educação Especial: Múltiplas Leituras e Diferentes Significados. Ed. Campinas-SP: Mercado de Letras, 2003, p. I79I9I.

SOUSA, S. Z. L.; PRIETO, R. G. A Educação Especial. In: OLIVEIRA, R. P.; ADRIÃO, T. Organização do Ensino no Brasil, Ed. São Paulo: Xamã, 2007, p. $123-135$.

Rodrigo Barroca Oliveira é graduando em Filosofia pela USP.

E-mail: barroquino@hotmail.com 